\title{
A ATUAÇÃO DO(A) PSICÓLOGO(A) ESCOLAR DIANTE DAS POLÍTICAS PÚBLICAS DE EDUCAÇÃO INFANTIL
}

\author{
Elysangela Koglin Ulo Limachi ${ }^{1}$ \\ Marcele Pereira da Rosa Zucolotto²
}

\section{RESUMO}

A Constituição Federal de 1988 estabelece que a criança brasileira seja um sujeito de direitos, sendo um destes o direito à Educação. Desde então, leis foram instauradas visando proporcionar à criança uma Educação gratuita e de qualidade desde o seu nascimento. Para tanto, instituições de Educação Infantil são estabelecidas e os profissionais envolvidos têm suas práticas norteadas por políticas públicas educacionais. Inserida neste contexto, a Psicologia vem redefinindo sua atuação, deslocando-se de uma prática historicamente segregadora no campo educacional para uma atuação que busca considerar o contexto escolar como um todo. Este trabalho, resultado de um estudo qualitativ o bibliográfico, objetiv ou refletir sobre a atuação do (a) psicólogo(a) escolar na Educação Infantil, frente às políticas públicas estabelecidas para este campo. Pôde-se perceber a amplitude da atuação deste profissional no contexto da Educação Infantil e também o alinhamento tão necessário entre os princípios norteadores das políticas públicas para Educação Infantil e aqueles que norteiam a atuação do(a) psicólogo(a) como profissional, principalmente no que diz respeito à busca por condições de cidadania dos sujeitos que fazem/frequentam a Educação Infantil.

Palavras-chave: Educação Infantil. Políticas Públicas. Psicologia Escolar.

\section{THE PERFORMANCE OF THE SCHOOL PSYCHOLOGIST IN RELATION TO THE PUBLIC POLICIES OF EARLY CHILDHOOD EDUCATION}

\begin{abstract}
The Federal Constitution of 1988 establishes that the Brazilian child is a subject of rights, one of these being the right to education. Since then, laws have been introduced to provide the child with a free and quality education from birth. In order to do so, institutions of early childhood education are established, and the professionals involved have their practices guided by public educational policies.
\end{abstract}

\footnotetext{
${ }^{1}$ Graduanda do Curso de Psicologia da Universidade Franciscana (UFN), Santa Maria/RS, Brasil. ORCID iD: https://orcid.org/0000-0002-6085-5292. E-mail: pselysangela@gmail.com

2 Doutora em Psicologia Social e Institucional (UFRGS). Professora do Curso de Psicologia e do Mestrado em Ensino de Humanidades e Linguagens da Universidade Franciscana (UFN), Santa Maria/RS, Brasil. ORCID iD: https://orcid.org/0000-0002-6856-8626. E-mail: marcelepr@hotmail.com
} 
Inserted in this context, psychology has been redefining its performance, shifting from a historically segregating practice in the educational field and turning to an action that seeks to consider the school context as a whole. This work, based on a qualitative bibliographical study, aimed to reflect on the performance of the school psychologist in child education in relation to the public policies established for this field. It was possible to perceive the breadth of the performance of this professional in the context of child education and also the necessary alignment between the guiding principles of public policies for early childhood education and the principles of psychologists' performance, especially with regard to the search for conditions of citizenship of the subjects that make/attend early childhood education.

Keywords: Child Education. Public Policies. School Psychology.

\section{LA ACTUACIÓN DEL (DE LA) PSICÓLOGO(A) ESCOLAR FRENTE A LAS POLÍTICAS PÚBLICAS DE EDUCACIÓN INFANTIL}

\section{RESUMEN}

La Constitución Federal de 1988 establece que el niño brasileño es un sujeto de derechos, siendo uno de éstos el derecho a la Educación. Desde entonces, se han instaurado leyes para proporcionar al niño una educación gratuita y de calidad desde su nacimiento. Para ello, se establecen instituciones de Educación infantil y los profesionales inv olucrados tienen sus prácticas orientadas por políticas públicas educativas. En este contexto, la Psicología viene redefiniendo su actuación, desplazándose de una práctica históricamente segregadora en el campo educativo y dirigiéndose para una actuación que busca considerar el contexto escolar como un todo. Este trabajo es el resultado de un estudio cualitativo bibliográfico cuyo objetivo fue reflexionar sobre la actuación del(de la) psicólogo(a) escolar en la Educación Infantil frente a las políticas públicas establecidas para este campo. Se pudo percibir la amplitud de la actuación de este profesional en el contexto de la Educación Infantil y también el alineamiento tan necesario entre los principios orientadores de las políticas públicas para Educación Infantil y los principios de actuación del(de la) psicólogo(a) como profesional, principalmente en lo que se refiere a la búsqueda por condiciones de ciudadanía de los sujetos que hacen/frecuentan la Educación Infantil.

Palabras clave: Educación Infantil. Políticas Públicas. Psicología Escolar.

\section{INTRODUÇÃO}

Até final do século XIX, o cuidado e a educação das crianças eram realizados no âmbito familiar, especialmente pela mãe. No entanto, com a industrialização e a consequente entrada das mulheres no mercado de trabalho, este cuidado foi sendo transferido para o que se conhece hoje por creches e pré-escolas (ZENDRON et al., 2013). Estas instituições deveriam (devem) zelar pelos cuidados básicos e segurança de crianças que, 
maiormente, eram (e, às vezes ainda são) oriundas de famílias com poucos recursos financeiros, em função disso, um caráter assistencialista permeou, inicialmente, a conduta destes espaços de educação infantil (MACARINI; MARTINS; VIEIRA, 2009; VIEIRA; HANSEN; VIEIRA, 2009; ZENDRON et al., 2013).

Atualmente, com as crescentes mudanças culturais $e$ socioeconômicas, há também um aumento no interesse para com a educação das crianças, assim sendo, aspectos psicopedagógicos começaram a ser enfatizados no cotidiano das instituições de Educação Infantil. Neste contexto, a preocupação não se atém apenas no cuidado das crianças, mas também na formação educacional das mesmas (ZENDRON et al., 2013).

Concomitantemente, a Psicologia, como ciência e profissão, vem inserindo-se gradativamente neste contexto - o escolar. Desde o século XIX, trabalhos da Psicologia passaram a demonstrar a preocupação com a aprendizagem da criança na escola, sendo que, em muitos estudos a atenção se voltava para o "desenvolvimento de instrumentos psicométricos capazes de avaliar a inteligência humana" (BARBOSA; MARINHO-ARAÚJO, 2010, p. 394). Especificamente no Brasil, a Psicologia surgiu e se desenvolveu primeiramente, para atender aos problemas da educação, com foco na medição do desenvolvimento mental, aprendizagem e maturidade para leitura e escrita. Contudo, Macarini, Martins e Vieira (2009) salientam a importância de serem revistas as práticas do profissional da Psicologia, para que não se detenham, simplesmente, no conhecimento técnico e sua aplicação. Suas ações no campo educacional, segundo Patto (2010), devem se voltar, prioritariamente, à promoção do desenvolvimento de todos. Ferreira $(2015$, p. 43) enfatiza que

Cabe ao psicólogo defender o desenvolvimento de todos naquilo que os torna humanos, contribuindo para a formação de homens culturais com a sociedade, com a coletividade não alienada.

Isto significa que o(a) psicólogo(a) no contexto escolar deve contribuir, por meio de suas intervenções, para a formação de pessoas (desde crianças 
na Educação Infantil) não inscientes, mas, comprometidas com a sociedade como um todo. A escola pode ser um dos meios importantes para garant ir a construção da cidadania dos sujeitos em que nela estão inseridos e, neste espaço, o(a) psicólogo(a) escolar pode ser um dos agentes que busca remover os obstáculos que impedem o desenvolvimento de um pensamento crítico (PATTO, 1984).

Com o advento da Constituição de 1988 (BRASIL, 1988), a criança passou a ser considerada um sujeito de direitos e sua educação um dever do Estado (além da família), desde a primeira infância - de zero a cinco anos. Diretrizes e referenciais curriculares nacionais são estabelecidos visando o pleno desenvolvimento da criança, tanto no aspecto físico, quanto psicológico, intelectual e social (ZENDRON et al., 2013). Decorrente deste processo, houve um aumento de instituições públicas e a Educação Infantil passou a ser considerada a primeira etapa da Educação Básica nacional. Nesse novo modelo de educação, as crianças passam a ser vistas como sujeitos históricos e culturais, "necessitando do adulto e do meio para interagir com o mundo e construir sua identidade pessoal e coletiva" (ZENDRON et al., 2013, p. 109).

Assim, no interesse de alcançar a todos os cidadãos, desde a mais tenra idade, com uma educação de qualidade, visando não apenas o conhecimento, mas também a construção da cidadania e a democratização do ensino, o governo federal vem estabelecendo políticas públicas que abarcam o contexto da Educação no Brasil. Estas políticas têm procurado tornar a educação e a escola acessiveis a todos os cidadãos, especialmente as crianças entre zero a cinco anos, ampliando a qualidade e o número de vagas em instituições de Educação Infantil.

Em vista disto, este estudo tem como objetivo refletir sobre a atuação do(a) psicólogo(a) escolar no campo da Educação Infantil, diante das políticas públicas estabelecidas para esta esfera educacional no Brasil. Assim, a partir de um estudo qualitativo bibliográfico, delimitou-se o trabalho em três aspectos: em um primeiro momento, inteirar-se dos princípios norteadores que regem as políticas públicas para Educação Infantil, bem 
como algumas de suas limitações na atualidade. Em um segundo momento, procurou-se retratar as relações históricas entre a escola e a atuação da Psicologia; para então, em um terceiro momento, fazer uma breve reflexão sobre a atuação do(a) psicólogo(a) escolar diante das políticas públicas para a Educação Infantil na contemporaneidade.

Estas reflexões despontam na intenção de que não apenas se reconheça a importância do(a) psicólogo(a) escolar na Educação Infantil, senão que também se apreenda e amplie este conhecimento sobre as diferentes possibilidades de sua atuação frente as políticas públicas educacionais brasileiras. Isto, para que este profissional não simplesmente cumpra com o que foi estabelecido pela lei brasileira, mas sim e ainda mais, contribua para a construção de uma Psicologia Escolar, conforme mencionam Antunes (2008) e Patto (2010), comprometida socialmente com a construção da cidadania da população no Brasil.

\section{SITUANDO AS POLÍTICAS PÚBLICAS PARA EDUCAÇÃO INFANTIL: PRINCÍPIOS E LIMITAÇÕES}

Uma concepção assistencialista permeou as práticas iniciais de atendimento às crianças pequenas no Brasil. As instituições - como creches e programas de pré-escolas - tinham o objetivo exclusivo de atender crianças oriundas de famílias de baixa renda, sendo muitas vezes um atendimento precário e insuficiente, mesmo naquelas mantidas pelo poder público (BRASIL, 1998). Instituições como essas, de caráter/concepção assistencial, motivaram, com sua prática, exclusão e estigmatização desta população, desconsiderando questões de cidadania, como liberdade e igualdade.

Entretanto, a partir de importantes mudanças sociais e políticas em nosso país, principalmente, aquelas decorrentes do contexto que levou ao estabelecimento da Constituição Federal de 1988 (BRASIL, 1988), propostas atuais para Educação Infantil têm se constituído visando modificar esta concepção assistencialista de atenção, voltando-se para uma ênfase no aspecto educacional da criança. Como consequência, a Educação Infantil passa ter uma função específica, como etapa inicial da Educação Básica, 
devendo "iniciar a formação necessária a todas as pessoas para que possam exercer sua cidadania" (BRASIL, 2006b, p. 32).

Por tal motivo, discussões e reflexões têm sido feitas buscando compreender a criança como este ser singular, social e histórico, capaz de construir seu conhecimento através das interações que estabelece com os outros como, por exemplo, escola, família e amigos. Este conhecimento e reconhecimento da criança, de ser e estar no mundo, tem sido um dos muitos desafios da Educação Infantil (FERREIRA, 2015; ANTUNES 2008; BRASIL, 1998; VOKOY; PEDROZA, 2005). Para tanto, as instituições e profissionais que atendem as crianças nest a faixa etária (zero a cinco anos) devem possibilitar o desenvolvimento integral das mesmas, em seus aspectos físico, psicológico, intelectual e social.

Neste sentido, torna-se importante tecer algumas considerações sobre a construção histórica e social das políticas públicas referentes à Educação Infantil no cenário de nosso país. Assim, a Declaração Universal dos Direitos Humanos e dos Direitos da Criança e do Adolescente contribuíram para que as crianças fossem mundialmente reconhecidas como cidadãs e portadoras de direitos. E, no Brasil, a Constituição Federal de 1988 demarcou o compromisso do Estado para com as mesmas, declarando-as como cidadãs plenas de direitos (BRASIL, 1988).

O Estatuto da Criança e do Adolescente em 1990 (BRASIL, 1990) vem corroborar e assegurar esses direitos e a Lei de Diretrizes e Bases da Educação Nacional (LDBEN), a Lei 9394/96, torna a educação um direito à infância, deliberando o direito das crianças de zero a cinco anos de idade à Educação Infantil (BRASIL, 1996). Também, a partir da LDBEN, a Educação Infantil passa a ser considerada a primeira etapa da Educação Básica (BRASIL, 1996) e, deste modo, o trabalho pedagógico realizado com as crianças pequenas ganha importância e reconhecimento, o que contribui para ultrapassar a visão de um trabalho voltado tão-somente para as práticas de cuidado. A gratuidade desse atendimento pelo governo é estabelecida e creches e pré-escolas passam a ser consideradas instituições de Educação Infantil, sendo a faixa etária o fat or que as dist ingue: creches - 
de zero a três anos - e pré-escolas - de quatro a cinco anos e onze meses de idade.

A responsabilidade por oportunizar a Educação Infantil é estabelecida pela LDBEN aos governos municipais (BRASIL, 1996) podendo estes, integrarem-se ao sistema estadual de ensino, para compor um sistema de educação básica. A União se incorpora neste processo como colaboradora (tanto dos estados, como municípios e Distrito Federal), para nortear os currículos, assegurando a formação básica comum (BRASIL, 1996). Deste modo, o Ministério da Educação (MEC) tem como responsabilidade a "indução, proposição e avaliação das políticas públicas relativas à Educação Nacional" (BRASIL, 1998, p. 12).

Desde a promulgação da LDBEN, em 1996, portanto, diversas ementas, diretrizes e resoluções vêm contribuindo para a efetivação da Educação tal como esta lei preconiza. E, neste processo, tendo em vista que a Educação Infantil passa a ser incorporada ao sistema de ensino do país, em 1998, são estabelecidos os Referenciais Curriculares Nacionais para a Educação Infantil, no intuito de auxiliar o professor e as ações pedagógicas (BRASIL, 1998). Em três volumes, este material visa garantir o desenvolvimento integral das crianças, reconhecendo seus direitos como cidadãos e contribuindo "com a implantação e/ou implementação de práticas educativas de qualidade que possam promover e ampliar as condições necessárias para o exercício da cidadania das crianças brasileiras" (BRASIL, 1998, p. 15).

Todas estas ações não centraram sua atenção apenas no contexto urbano, mas também, nas escolas de Educação Infantil no contexto indígena e rural. Isso porque, estas políticas visam também respeitar e considerar a pluralidade e diversidade do país, de seus cidadãos, desde os menores até os maiores em idade. Os projetos e programas curriculares desenvolvidos precisam ser condizentes com as realidades e peculiaridades de cada região e com os sujeitos ali presentes. Por conseguinte, para oferecer uma educação de qualidade à população infantil brasileira, é preciso considerar as especificidades tanto afetivas quanto emocionais, cognitivas e sociais destas crianças e possibilitar experiências que 
contribuam para o exercício da cidadania primando sempre pelos seguintes princípios explicitados pelo Referencial Curricular para Educação Infantil, volume I (BRASIL, 1998, p. 15):

\footnotetext{
- O respeito à dignidade e aos direitos das crianças, consideradas nas suas diferenças individuais, sociais, econômicas, culturais, étnicas, religiosas etc.;

- O direito das crianças a brincar, como forma particular de expressão, pensamento, interação e comunicação infantil;

- O acesso das crianças aos bens socioculturais disponíveis, ampliando o desenvolvimento das capacidades relativas à expressão, à comunicação, à interação social, ao pensamento, à ética e à estética;

- A socialização das crianças por meio de sua participação e inserção nas mais diversificadas práticas sociais, sem discriminação de espécie alguma;

- O atendimento aos cuidados essenciais associados à sobrevivência e ao desenvolvimento de sua identidade.
}

Posteriormente, em 1999, o Conselho Nacional de Educação (CNE), no âmbito da Câmara de Educação Básica (CEB), estabelece as Diretrizes Curriculares Nacionais para a Educação Infantil (BRASIL, 1999). De caráter mandatório para todos os sistemas municipais e/ou estaduais de educação e reconhecendo a criança como um sujeito de direitos, estas Diretrizes estabelecem os fundamentos que devem orientar tanto os projetos pedagógicos, como também a organização das próprias instituições de Educação Infantil. Estes fundamentos são assim definidos pelas Diretrizes (BRASIL, 1999. Art. 30):

I. Princípios Éticos da Autonomia, da Responsabilidade, da Solidariedade e do Respeito ao Bem Comum;

II. Princípios Políticos dos Direitos e Deveres de Cidadania, do Exercício da Criticidade e do Respeito à Ordem Democrática;

III. Princípios Estéticos da Sensibilidade, da Criatividade, da Ludicidade e da Diversidade de Manifestações Artísticas e Culturais.

Além disso, tem-se em 2001 o Plano Nacional de Educação (BRASIL, 2001) e, em 2006, a Política Nacional de Educação Infantil (BRASIL, 2006a), recolocando a importância do direito da criança de zero a cinco anos à educação. Em cumprimento ao Plano Nacional de Educação e à Política 
Nacional de Educação Infantil, ainda em 2006, são publicados os Parâmetros Nacionais de Qualidade da Educação Infantil (BRASIL, 2006b), trazendo motes fundamentais para a qualificação da Educação Infantil. Posteriormente, em 2009, são publicados os Indicadores da Qualidade da Educação Infantil (BRASIL, 2009a) e, ainda neste mesmo ano, o parecer CNE/CEB n. 20/2009, que fixa as Diretrizes Curriculares Nacionais Para a Educação Infantil (BRASIL, 2009b).

Com o propósito de ampliar o entendimento sobre as políticas que regem a Educação Infantil no país, é importante considerar, que esta vem sofrendo recentemente, importantes alterações. Nesta direção, a Lei n. 11.274/2006 antecipou o acesso ao ensino fundamental para 6 anos de idade e, por este motivo, a Educação Infantil passa a atender a faixa etária de zero a cinco anos e onze meses (BRASIL, 2006c). Além desta, a Lei $n$. 12.796/2013 passou a tornar obrigatória a matrícula de todas as crianças de quatro a cinco anos de idade nas instituições de Educação Infant il (BRASIL, 2013). Em meio a muitas discussões e conflitos, O Plano Nacional de Educação de 2014 estabelece metas importantes para a Educação Infantil, como a ampliação da oferta do número de vagas nas creches e a universalização da educação infantil na pré-escola para as crianças de quatro a cinco anos de idade (BRASIL, 2014).

Considerando este panorama político da Educação Infantil no país, torna-se importante destacar que, mesmo diante da ênfase que foi dada, desde o início da década de 1990, ao atendimento e cuidado para com a primeira infância, Moreira e Lara (2012) lembram que as políticas relacionadas à Educação Infantil estão repletas de contradições. Dentre elas, Kramer (2006) salienta o fato de que, embora a Educação Infantil tenha um impacto significativo no desempenho escolar da criança, para alguns legisladores, isto ainda necessita ser comprovado. Também são cada vez mais necessários estudos e pesquisas que proponham novas práticas e metodologias para que a Educação Infantil seja uma parte consistente na luta contra a desigualdade. 
Além disso, é pertinente acrescentar que, para que a Educação Infantil seja efetiva e se torne um direito garantido, é preciso financiamento, democratização das creches e pré-escolas e formação continuada dos profissionais que atuam nestas instituições. Cerisara (2002) mostra que a LDBEN é omissa quanto ao financiamento para Educação Infantil, pois, mesmo com a criação posterior do Fundo de Manutenção e Desenvolvimento do Ensino Fundamental e de Valorização do Magistério (FUNDEF), os recursos ficaram restritos à responsabilidade dos governos municipais que deveriam se ocupar com o Ensino Fundamental, denotando com isso, a total falta de prioridade de qualquer instância da União para com a Educação Infantil. Moreira e Lara (2012) também fazem referência à ênfase governamental para com o Ensino Fundamental, fato este que resultou em um favorecimento de uma concepção de educação fragmentada, ao se priorizar uma etapa em detrimento de outra. Para as autoras, este fato acabou se constituindo em um dos motivos de descaso para com a Educação Infantil.

Avaliando o RCNEl, Cerisara (2002) enfatiza os aspectos restritivos do mesmo, pois ainda é preciso construir um trabalho que respeite as "especificidades e diversidades culturais das crianças sem que haja a proclamação de um modelo único e verdadeiro" (CERISARA, 2002, p. 340). Este trabalho precisa garantir que as crianças vivam sua infância sem que fiquem aprisionadas a rotinas escolares inflexíveis. As instituições de Educação Infantil necessitam proporcionar um espaço para a vida, para as relações entre pares, onde se constroem o respeito, a compreensão, a criatividade, a confiança, a solidariedade. Segundo Cerisara (2002), o RCNEl, apesar de ser um avanço na construção de um documento que se diz voltado para Educação Infantil, ainda não garante plena e efetivamente as especificidades das crianças de zero a cinco anos. Acrescenta a autora que sua implementação não se deu verdadeiramente através de debates e discussões sobre o tema, conforme o próprio documento salienta (BRASIL, 1998), sendo veiculado antes mesmo da publicação das DCNEI. 
Além disso, Rocha (2009) acrescenta, como outro problema encontrado no âmbito das políticas públicas da Educação Infantil, a própria definição de infância. Para o Estatuto da Criança e Adolescente (Brasil, 1990), a infância vai até os 12 anos, sendo que a Educação Infantil considera infância o período de 0 a 6 anos. Deste modo, Rocha (2009) comenta o quanto as leis brasileiras que tratam da Educação Infantil limitam demais a infância em termos de idade. A preocupação do autor refere-se à "necessidade do ensino fundamental não perder a dimensão que o direciona à formação da criança, ainda no estágio infantil" (ROCHA, 2009, p. 54). Neste sentido, considera-se que, apesar de uma organização educativa diferenciada e uma legislação educacional considerada avançada (MOREIRA; LARA, 2012), ainda resta um longo percurso em nosso país para que a Educação Infantil, como um direito, se concretize na prática.

\section{PSICOLOGIA, EDUCAÇÃO E ESCOLA: histórias e relações}

A Psicologia e a Educação caracterizam-se como campos de saberes e práticas que, historicamente, têm estabelecido entre si relações amplas e complexas. Para Antunes (2008), a história da Psicologia articulada com a escola e com a educação no Brasil pode ser identificada desde os tempos coloniais. Já naquele momento, estudos como aprendizagem, personalidade, educação de mulheres e de indígenas começavam a fazer parte do repertório que, mais tarde, tornar-se-iam campos de estudos e atuação da psicologia voltada para a prática educativa. Antunes (2008, p. 470) destaca que, naquele momento, "a maioria desses escritos estava comprometida com os interesses metropolitanos e expressava as mazelas de sua dominação na colônia".

Nesta perspectiva, e seguindo uma linha temporal de construção teórica e prática da psicologia escolar e educacional, pode-se dizer que, já nos anos finais do século XIX, as transformações sociais e o fortalecimento dos ideais liberais exigiam mudanças na sociedade como um todo, colocando a necessidade de um novo homem, cuja formação deveria ser 
proporcionada pela educação. Saberes pedagógicos e saberes psicológicos sobre o homem passam a ser promovidos e articulados, de modo que Antunes (2008) menciona que tanto a Educação foi base para o desenvolvimento da Psicologia, quanto esta ciência fundamentou a primeira, sendo consideradas, portanto, constituintes entre si.

No entanto, o processo de construção e consolidação da Psicologia no campo da Educação foi historicamente marcado por objetivos fortemente adaptacionistas, detendo-se, muitas vezes, a reproduzir o discurso vigente da ordem e das normatizações. A figura do(a) psicólogo(a) escolar, ainda pouco definida neste contexto, estava relacionada a "curar" o(a) aluno(a)-problema, resolvendo dificuldades de aprendizagem que surgiam na escola. A ele(a) também era comissionada a tarefa de mensurar capacidades e aplicar testes psicológicos, visando aumentar a produtividade do grupo de estudantes (MARINHO-ARAÚJO; ALMEIDA, 2008; SILVANA; OLIVEIRA, 2017).

Vários estudos registram que esta conduta focada naqueles(as) que não aprendiam, que não se alfabetizavam ou que não obedeciam às regras escolares, fomentou uma Psicologia segregadora e excludente. Isto contribuiu para o surgimento de uma política de apartações dentro da escola, a partir da qual passam a ser definidos os(as) que aprendem e os(as) que não aprendem; os(as) aptos(as) e os(as) não aptos(as) a aprender determinadas atividades ou tarefas (FERREIRA, 2015; ANDRADA, 2005; ANTUNES 2008; SOUZA et al., 2014).

Nesta visão de trabalho, o(a) profissional psicólogo(a) teve seu lugar garantido em uma sala dentro do ambiente escolar, nada diferente do atendimento feito em um consultório fora da escola, reproduzindo uma típica atuação baseada em uma perspectiva linear do(a) aluno(a)problema, sendo ele(a) o(a) único(a) responsável por suas deficiências ou falhas. Portanto, deveria este(a) profissional 'trabalhar' com este (a) aluno(a) para que, retomando suas capacidades de aprendizagem, o(a) mesmo(a) pudesse se readaptar às normas e ao ambiente escolar como um todo (ANDRADA, 2005). 
Entretanto, esta atuação da Psicologia na escola demarcou uma postura extremamente segregadora na compreensão das dificuldades escolares, demarcando o próprio sujeito como o responsável pela não aprendizagem e desconsiderando uma gama complexa de fatores que determinavam 0 aprender na escola. Nesta perspectiva, a Psicologia acabou instaurando um modelo de atuação individualizante e clínicoterapêutico, voltado exclusivamente para os problemas psíquicos que impediam o sujeito de aprender. Uma atuação voltada à manutenção da ordem escolar, por meio do reajustamento dos indivíduos desviantes, vendo neles próprios - e, no máximo em suas famílias - as causas desse desajuste de aprendizagem.

Não obstante, no que diz respeito à Psicologia Escolar, esta vem se redefinindo desde este modelo de atuação individualista e adaptacionista, para um modelo que busca se aproximar cada vez mais do dia a dia escolar, requerendo de seus profissionais um posicionamento mais crítico diante do processo de escolarização (SOUZA et al., 2014). A partir disso, o(a) psicólogo(a) já não deve manter aquela visão linear de trabalho, mas atuar no sentido de observar esses(as) 'alunos(as)-problema' dentro de todo seu contexto social, atentando para a realidade escolar na qual estão inseridos(as) (ANDRADA, 2005).

Novos modelos de atuação passam a salientar que, na verdade, não se trata de desconsiderar a importância da dimensão psicológica individual para os processos educativos e desresponsabilizar inteiramente o sujeito, quanto aos problemas escolares, mas, de entender que estas questões psicológicas são apenas parte do complexo processo educativo. Nesta direção, tanto as questões sociais, como econômicas, culturais e as pedagógicas, devem ser levadas em conta para o entendimento das dificuldades de ajustamento ou aprendizagem que surgem no campo escolar. Assim, a Psicologia permanece, sim, como um dos fundamentos da educação, buscando, no entanto, ampliar suas bases de compreensão destes problemas, deslocando o olhar unicamente para o sujeito e fazendo perceber outros fatores e relações escolares como um todo. 
Além disso, ponderando sobre a função da escola na comunidade, esta surge na história humana como uma instituição construída para responder às necessidades da sociedade. Assumindo diversas formas para atender a estas, foi se articulando aos interesses de uma classe dominante e com isso limitou, inicialmente, seu atendimento a uns poucos privilegiados da população (ANTUNES, 2008). Refletindo nesta direção, Antunes (2008) salienta que a Educação deve ser compreendida/entendida como uma prática social que precisa constituir-se como um agente de democratização e cidadania. Marinho-Araújo; Almeida (2008) reconhecem também esta função política da escola, na qual se pode/deve discutir e exercer a cidadania em prol de uma sociedade mais justa.

Torna-se fundamental debater e refletir acerca do papel da escola como agente de democratização e importante produtora de cidadania aos sujeitos sociais, pois este refletirá também na definição do papel do(a) psicólogo(a) atuante na escola (FERREIRA, 2015). Este(a) profissional precisa estar comprometido(a) com a garantia da cidadania e dos direitos humanos daqueles que ali estão inseridos. Por esta razão, se faz necessária uma Psicologia Escolar que se contraponha àquele passado recente (com ênfase numa atuação segregadora e individualizada), considerando os diferentes contextos e relações que envolvem os sujeitos escolares. Em conjunto a isto, pode-se ampliar o campo de ação deste(a) profissional envolvendo também as diversas (inter)relações presentes no contexto escolar e inclusive comunitário (VOKOY; PEDROZA, 2005).

Assim, buscando abandonar uma prática antes focada em uma atenção individualizada aos distúrbios e problemas apresentados pela criança, hoje o(a) psicólogo(a) escolar se vê desafiado(a) a ampliar sua atuação incluindo outras formas de intervenção, como a preventiva e a comunitária (COSTA; GUZZO, 2006). Uma atuação preventiva está baseada em quatro ações principais: 1) mapeamento e análise da instituição para assimilar a realidade escolar ali presente; 2) promoção de espaços de escuta psicológica, a fim de compreender as relações interpessoais existentes na escola; 3) planejamento coletivo dos trabalhos desenvolvidos 
na escola e assessoria dos mesmos e por fim; 4) auxiliar/acompanhar no processo de ensino-aprendizagem (CFP, 2013). Já em uma atuação comunitária, suas ações se estendem a toda comunidade, tanto dentro, como fora da escola (SILVANA; OLIVEIRA, 2017). Marinho-Araújo; Almeida (2008) também salientam que a atuação do(a) psicólogo(a) escolar precisa caracterizar-se por uma intervenção mais "dinâmica, participativa e sistemática na instituição" (MARINHO-ARAÚJO; ALMEIDA, 2008, p. 89), articulando-se à realidade do seu contexto.

Finalizando estas colocações, vale expor o que o Conselho Federal de Psicologia, em suas Referências Técnicas para atuação de Psicólogas (os) na Educação Básica, considera acerca da atuação do(a) psicólogo(a) escolar no contexto da Educação como um todo:

Portanto, a finalidade da atuação da (o) psicóloga (o) na Educação deve se pautar no compromisso com a luta por uma escola democrática, de qualidade, que garanta os direitos de cidadania a crianças, jovens e profissionais da Educação. Esse compromisso é político e envolve a construção de uma escola participativa, que possa se apropriar dos conflitos nela existentes através da implicação de todos os seus atores (CFP, 2013, p. 72).

\section{A ATUAÇÃO DO(A) PSICÓLOGO(A) ESCOLAR E AS POLÍTICAS PÚBLICAS VIGENTES PARA EDUCAÇÃO INFANTIL}

Se a história da Psicologia no contexto escolar foi marcada por uma conduta que contribuiu para a segregação de crianças, seja por suas condições sociais ou pelos problemas de aprendizagem ou de ajustamento, hoje é o momento para se formular uma nova atuação e apresentar novas práticas que estejam em sintonia com os objetivos das atuais políticas públicas para Educação Infantil, continuamente, refletindo acerca de seu papel social neste contexto (FERREIRA, 2015; CFP, 2013; PATTO, 2010).

Assim, mediante essas políticas públicas, o(a) psicólogo(a) deve necessariamente rever sua história profissional, marcada por práticas individualizadas, normativas e adaptacionistas. Deve, fundamentalmente, resgatar a dimensão social e cultural dos problemas escolares, ampliando seu campo de visão sobre o ato educativo, para além do subjetivismo que 
marcou e motivou os estudos e as práticas iniciais da Psicologia, no campo escolar e educacional. Para contribuir na efetivação das políticas públicas para a Educação Infantil, o(a) psicólogo(a) deverá dispor de uma atuação que, ao invés de reproduzir segregações, venha fortalecer a construção de sujeitos com plena cidadania. Mas, além disso, deve lutar para que todos, no espaço da Educação Infantil, possam se comprometer para a construção de uma escola democrática e, prioritariamente, voltada para a formação cidadã.

E, assim como é propósito das políticas públicas na área da Educação Infantil possibilitar o desenvolvimento integral da criança, primando pelo exercício da plena cidadania, a psicologia escolar também destaca a importância de se promovê-la, reconhecendo e contemplando as especificidades sociais e culturais de cada criança (COSTA; GUZZO, 2006; BRASIL, 2006). Para isso, o(a) psicólogo(a) precisa assumir seu lugar na escola, reconhecendo a complexidade do processo educativo e do cotidiano escolar e, diante disso, buscar fomentar (e contribuir para) o estabelecimento de práticas de autonomia e de expressão das crianças no espaço da escola infantil.

Atuar dentro do contexto específico da Educação Infantil envolve, ainda e sobretudo, a necessidade de um conhecimento global do desenvolvimento da criança, percebendo-a como um sujeito da educação compreendido por uma integralidade de fatores, "sem dissociar seus aspectos cognitivos, afetivos, expressivos, motores ou simbólicos" (VOKOY; PEDROZA, 2005, p. 96). A criança é, além de um sujeito de direitos, um ser histórico, social, produto de nossa cultura e, principalmente, produtora de relações culturais. Ela não é um corpo inerte, incompleto, preparando-se para ser algo somente no futuro. Ela é ser do presente, sujeito pleno de vontades e de competências para produzir, ativa e criticamente, sentidos e experiências sobre o mundo. Daí, portanto, a necessidade de que a Psicologia venha contribuir para colocá-la no centro do processo educativo na Educação Infantil. 
A questão do protagonismo infantil, muito além de ser um novo modismo conceitual, se torna importante por buscar reinserir a criança no cerne da discussão, como sujeito pleno de um arsenal de potencialidades para ser, criar e construir novas maneiras de ver o mundo, de aprender e se relacionar. No entanto, talvez muito pouco se tem feito para que, de fato, os adultos e educadores possam se relacionar com este novo conceito de criança. Vemos escolas preocupadas, quase exclusivamente, em fornecer ferramentas para a construção de saberes que mais adiante, no ensino fundamental, serão priorizados, como o letramento e alfabetização. Talvez seja o momento de perceber que o protagonismo infantil poderá ser o conceito capaz de fundamentar novas maneiras de educar, levando a sério o quanto a criança realmente pode participar de seu próprio processo de formação. A Psicologia, no campo da Educação Infantil, relembra o quanto esta existe para a infância, ressaltando-a como eixo norteador das práticas escolares.

A Educação Infantil se torna, para a Psicologia, o momento fundamental em que a criança realiza as suas primeiras interações com outros sujeitos que não fazem parte de seu contexto familiar, sendo a ocasião em que se amplia sua rede de relações, o que contribui significativamente para a formação de sua subjetividade, além de colaborar na constituição das bases para seus processos de produção de conhecimentos. Por estes motivos, a Educação Infantil passa a ser defendida pela Psicologia tal como ela se coloca nas políticas públicas que a norteiam: não como mero favor assistencialista, mas, como direito necessário da criança.

Neste sentido, segundo as Referências Técnicas para atuação de Psicólogas(os) na Educação Básica, a prática do(a) psicólogo(a) escolar deve ser aquela que conduza a criança a descobrir seu potencial de aprendizagem (CFP, 2013). O(a) psicólogo(a), no campo da Educação Infantil, tem o dever de contribuir para a participação e para a expressão da criança em seu processo educativo. E, além disso, o saber da Psicologia é de significativa importância para a compreensão das especificidades da 
infância, por todos aqueles que fazem o cotidiano da Educação Infantil, sendo que o(a) psicólogo(a) deve atuar no sentido de uma necessária conscientização de todos os envolvidos neste contexto, de que cada ação/intervenção, neste momento da vida da criança, também pode ter consequências para o futuro desta. Portanto, a Psicologia deverá enfatizar o quanto a Educação Infantil possui um valioso papel na construção da subjetividade desde a infância, além de permitir a convivência com iguais e, assim, ampliar as relações do contexto social da criança.

Nesta direção, seria preciso lembrar, ainda, que os grandes avanços em termos de políticas públicas para a Educação Infantil, principalmente, desde a década de 90, culminaram também em mudanças no atendimento às crianças. Se antes o cuidado era suficiente, hoje o mesmo deve ser vinculado às práticas educativas e, assim, educação e cuidados deverão, necessariamente, ser articuladas no contexto da Educação Infantil. A atuação da Psicologia, diante disso, será no sentido de favorecer discussões e práticas que visem a defesa da indissociabilidade entre estes fatores e, mais do que isto, contribuir para que, nesta articulação, a própria criança não seja esquecida em meio a exigências e práticas.

Cabe ao(à) psicólogo(a) escolar que atua no contexto da Educação Infantil proporcionar, com seus conhecimentos e práticas, interação e integração nas relações sociais existentes neste contexto, pois delas (relações sociais) decorrem processos de desenvolvimento e aprendizagem. Consequentemente, este profissional tem sua atuação ampliada, não apenas focada na criança em si, mas também, nas relações que estabelecem com o meio. Nesta direção, espaços de escuta, encontros grupais, acolhimento às famílias, trocas formativas com professores(as), dentre outras atividades, são algumas ações deste(a) profissional que muito podem contribuir para o crescimento de todos os envolvidos neste contexto (MACARINI; MARTINS; VIEIRA, 2009), primando por um caminho que conduza à autonomia e à construção e vivência da cidadania.

Patto (2010) e Souza et al. (2014) reforçam o posicionamento crítico e político que deve ter o(a) psicólogo(a) escolar, devendo este(a) ser um(a) 
agente de mudanças qualitativas no contexto educacional, colaborando e lutando "pela transformação das relações sociais" (SOUZA et al., 2014, p. 133). O(a) psicólogo(a) escolar deverá priorizar a construção de espaços e de possibilidades para que todos os personagens envolvidos com a Educação Infantil possam ter voz, para que sejam ouvidas suas questões e/ou seus posicionamentos, sejam dos personagens atuantes dentro ou fora da escola, sejam professores, familiares, gestores ou - inclusive e priorit ariamente - as próprias crianças.

Considerando a especificidade da Educação Infantil, o(a) profissional da Psicologia pode atuar ainda no processo de mediação escola-família, criando estratégias que fomentem a discussão de temas relacionados a este contexto específico, como práticas de cuidado, desenvolvimento infantil, relação infância-família, dentre outras (MACARINI; MARTINS; VIEIRA, 2009). Vieira; Hansen; Vieira (2009) também salientam essa atuação junto às famílias unindo-as à escola, principalmente, porque durante a vivência na Educação Infantil podem surgir períodos críticos, que podem ser amenizados através de uma ação que viabilize estratégias de ambientação e flexibilidade frente às adversidades. Segundo estes autores, o(a) psicólogo(a) escolar, ao intervir nestes momentos, pode contribuir para promover a saúde mental das crianças, buscando reduzir problemas futuros, numa atuação preventiva, contribuindo na construção de relações que visam evitar discriminações ou exclusões no contexto educacional.

Além disso, a atuação do(a) psicólogo(a) escolar na Educação Infantil deve estar fortemente ligada a um trabalho interdisciplinar participando, por exemplo, na "elaboração, avaliação e reformulação do Projeto Político Pedagógico, destacando a dimensão psicológica ou subjetiva da realidade escolar", e com isso, valorizando o trabalho docente (CFP, 2013, p. 54). Ainda nesta linha, salienta-se o quanto a atuação da Psicologia, no campo das políticas públicas da Educação Infantil, deverá estar pautada na luta pela qualificação e na formação inicial e continuada dos(as) docentes. Valorizar o(a) profissional da Educação Infantil é ação fundamental para se atingir 
uma competência técnica, capaz de estabelecer práticas cada vez mais eficazes para o pleno desenvolvimento das crianças pequenas no Brasil.

Além disso, importante sublinhar que "todas as políticas [públicas educacionais] implantadas no plano da reforma educacional investem no professor como aquele que terá a tarefa primordial de efetivá-la" (SOUZA, 2010, p. 138). Entretanto, embora os(as) professores(as) sejam trazidos(as) como elementos fundamentais para o sucesso de uma política pública educacional, pouca abertura se oferece para a verdadeira participação destes(as) profissionais, na construção ou mesmo na discussão das políticas públicas que irão reger suas práticas cotidianas. As decisões políticas acabam surgindo como imposições a seu trabalho, apontando para a subalternidade do pedagógico em relação ao político (SOUZA, 2010), o que explicita o quanto as políticas públicas, no campo educativo, não se estabelecem de modo coletivo e democrático, mas, surgem trazendo, muitas vezes, dificuldades e desamparo - prático e/ou conceitual - aos (às) professores (as) da Educação Infantil.

São reconhecidas, até o momento, a amplitude e a importância da atuação do(a) psicólogo(a) escolar no campo da Educação Infantil. A rede privada de ensino tem se beneficiado do trabalho deste(a) profissional incluindo-o(a) em seu quadro de funcionários, entretanto, Andrada (2005) se questiona acerca da ausência do referido profissional, na rede pública de ensino. Ferreira $(2015$, p. 40) procura responder a essa indagação, registrando que pela Lei de Diretrizes e Bases da Educação Nacional, o(a) psicólogo(a) "não é regulamentado como profissional da Educação", por isso, não pode ser contratado(a) pelas Secretarias Municipais de Educação. Todavia, para Silvana; Oliveira (2017), é preciso focar em políticas públicas que promovam ações mais efetivas no que se refere à atuação do(a) psicólogo(a) escolar na rede pública de ensino, especialmente na Educação Infantil.

\section{CONSIDERAÇÕES FINAIS}

Revista Exitus, Santarém/PA, Vol. 9, №3, p. 116 - 140, JUL/SET 2019. 
É momento de a Psicologia Escolar intensificar suas reflexões na busca de maior criticidade à sua formação e atuação, diante de um cenário político-econômico que agudiza, ainda que de forma cada vez mais sutil, o controle social e as graves desigualdades que se configuram no panorama histórico atual (MARINHO-ARAÚJO; ALMEIDA, 2008, p. 69).

No decorrer deste trabalho, pôde-se compreender a importância da presença e intervenção do(a) psicólogo(a) escolar, no contexto da Educação Infantil. Ele(a) é o(a) agente escolar que deve sempre contextualizar a realidade que o(a) envolve sem, no entanto, conformar-se aos padrões vigentes, que por vezes, cristalizam-se e se tornam obstáculos para o pleno desenvolvimento tanto da criança como dos demais inseridos neste contexto. É de fundamental importância a atuação da Psicologia voltada a contribuir para o desenvolvimento infantil, formando pessoas autônomas, críticas e cidadãs (BARBOSA; MARINHO-ARAÚJO, 2010; SILVANA; OLIVEIRA, 2017).

Segundo Silvana e Oliveira (2017) o(a) psicólogo(a) escolar deve agir de maneira cada vez mais expressiva para promover e consolidar seu ingresso no ambiente escolar. Antunes (2008) também salienta que o trabalho deste(a) profissional precisa estar efetivamente comprometido com o cotidiano da escola, promovendo uma educação democrática.

É fato que a rede privada de ensino já tem aberto (embora gradativamente) um espaço para atuação deste (a) profissional, mas, a rede pública, de muito maior abrangência e atendendo a um público muito maior, ainda carece da presença deste(a) profissional. Mesmo que o(a) psicólogo(a) não seja regulamentado como um(a) profissional da Educação, cabe lembrar que o Congresso Nacional já declarou que alunos das escolas públicas de educação básica têm assegurados por lei, o atendimento tanto por psicólogos(as) quanto por assistentes sociais (SILVANA; OLIVEIRA, 2017). Neste sentido, se faz necessário que os(as) psicólogos(as) escolares direcionem também suas práticas para a construção de políticas públicas que não só resultem em uma ação mais efetiva deste(a) profissional em seu contexto de trabalho - a escola, mas 
também ações comprometidas com as classes populares (ANTUNES, 2008; SILVANA; OLIVEIRA, 2017).

Em virtude do que foi exposto neste trabalho acerca da atuação do(a) psicólogo(a) escolar na Educação Infantil frente às políticas públicas vigentes nesta área, percebe-se a amplitude de seu trabalho neste contexto. Embora uma postura segregadora tenha marcado o início da caminhada deste(a) profissional no campo educacional, atualmente este quadro tem se revertido na direção de uma prática voltada para todo contexto social da criança. Uma prática não apenas focada nas dificuldades de um só indivíduo (a criança), mas também nos diversos conflitos e relações que o(a) cercam, envolvendo todo o contexto escolar.

Percebe-se também, o alinhamento tão necessário entre os princípios norteadores das políticas públicas para Educação Infantil e os princípios de atuação do(a) psicólogo(a) como profissional, principalmente no que diz respeito à busca por condições de cidadania dos sujeitos que fazem/frequentam a Educação Infantil. A congruência entre os princípios pode colaborar para uma prática mais justa e equitativa no contexto escolar.

Como profissional, o(a) psicólogo(a) escolar precisa manter sempre a disposição crítica e questionadora quanto à sua prática e frente às políticas públicas que são implantadas em seu contexto de atuação. Questionamentos levantados pela psicóloga escolar Maria Helena Souza Patto, na década de 80, tais como: O que fazemos? Para quem fazemos? Com que finalidade? A que interesses servimos? (PATTO, 1984) são totalmente pertinentes para o momento atual. Questionamentos como estes o(a) psicólogo(a) escolar, no contexto da Educação Infantil, precisa fazer continuamente, para que sua prática não retroceda ferindo seus preceitos éticos e consequentemente direitos civis e sociais tão arduamente conquistados.

\section{REFERÊNCIAS}

Revista Exitus, Santarém/PA, Vol. 9, №3, p. 116 - 140, JUL/SET 2019. 
ANDRADA, E. G. C. Novos paradigmas na prática do Psicólogo Escolar. Psicologia Reflexão e Crítica, v. 18, n. 2, p. 196-199, 2005.

ANTUNES, M. A. M. Psicologia escolar e educacional: história, compromissos e perspectivas. Psicologia Escolar e Educacional, v. 12, n. 2, p. 469-475, 2008.

BARBOSA, R. M.; MARINHO-ARAÚJO, C. M. Psicologia Escolar no Brasil: considerações e reflexões históricas. Estudos de Psicologia, v. 27, n. 3, p. 393402, 2010.

BRASIL. Constituição da República Federativa do Brasil. Brasília, DF: Senado Federal, 1988. Disponível em:

http://www.planalto.gov.br/ccivil_03/constituicao/constituicao.htm. A cesso em 17/10/2017.

BRASIL. Lei n. 8.069, de 13 de julho de 1990. Dispõe sobre o Estatuto da Criança e do Adolescente e dá outras providências. Diário Oficial da União. Brasília/DF, 16/7/1990. Disponível em

http://www.planalto.gov.br/ccivil_03/leis/L8069.htm. A cesso em 02/12/2017.

BRASIL. Lei n. 9.394, de 20 de dezembro de 1996. Estabelece as diretrizes e bases da educação nacional. Diário Oficial da União. Brasília/DF, 23/12/1996. Disponível em http://www.planalto.gov.br/ccivil_03/leis/L9394.htm. A cesso em 10/09/2017.

BRASIL. Ministério da Educação e do Desporto. Referencial Curricular Nacional para a Educação Infantil. Secretaria da Educação Fundamental. Brasilia: MEC/SEF, 1998.

BRASIL. Resolução CEB No 1, de 7 de abril de 1999. Institui as Diretrizes Curriculares Nacionais para a Educação Infantil. Diário Oficial da União. Brasília/DF, 13/04/1999. Disponível em http://portal.mec.gov.br/cne/arquivos/pdf/CEB0199.pdf. A cesso em 20/09/2017.

BRASIL. Lei $n^{\circ}$ 10.172, de 9 de janeiro de 2001. Aprova o Plano Nacional de Educação e dá outras providências. Diário Oficial da União. Brasília/DF, 10/01/2001.http://www.planalto.gov.br/ccivil_03/leis/leis_2001/110172.htm. A cesso em 20/01/2018.

BRASIL. Ministério da Educação/Secretaria da Educação Básica. Política Nacional de Educação Infantil: pelo direito das crianças de zero a seis anos à educação. Brasília: MEC/SEB, 2006a.

BRASIL. Ministério da Educação/Secretaria da Educação Básica. Parâmetros Nacionais de qualidade para a Educação Infantil. vol 1. Brasillia: MEC/SEB, 2006 b. 
BRASIL. Lei $n^{\circ} 11.274$, de 6 de fevereiro de 2006. Altera a redação dos arts. 29, 30, 32 e 87 da Lei no 9.394, de 20 de dezembro de 1996, que estabelece as diretrizes e bases da educação nacional, dispondo sobre a duração de 9 (nove) anos para o ensino fundamental, com matrícula obrigatória a partir dos 6 (seis) anos de idade. Diário Oficial da União. Brasília/DF, 07/02/2006. 2006c. Disponível em: http://www.planalto.gov.br/ccivil_03/_ato20042006/2006/lei/l1 1274.htm. Acesso em 17/01/2018.

BRASIL. Ministério da Educação/Secretaria da Educação Básica. Indicadores da Qualidade na Educação Infantil. Brasilia: MEC/SEB, 2009 a.

BRASIL. Resolução CNE/CEB n. 5, de 17 de dezembro de 2009. Fixa as Diretrizes Curriculares Nacionais para a Educação Infantil. Diário Oficial da União. Brasília/DF, 18/12/2009. 2009b. Disponível em:

http://portal.mec.gov.br/index.php?option=com_docman\&view=download \&alias=2298-rceb005-09\&category_slug=dezembro-2009-pdf\&ltemid=30192. A cesso em 10/02/2018.

BRASIL. Lei $n^{\circ}$ 12.796, de 4 de Abril de 2013. Altera a Lei n9.394, de 20 de dezembro de 1996, que estabelece as diretrizes e bases da educação nacional, para dispor sobre a formação dos profissionais da educação e dar outras providências. Diário Oficial da União. Brasília/DF, 05/04/2013. 2013. Disponível em: http://www2.camara.leg.br/legin/fed/lei/2013/lei-12796-4abril-2013-775628-publicacaooriginal-139375-pl.html. A cesso em 21/02/2018.

BRASIL. Lei n. 13.005, de 25 de junho de 2014. Aprova o Plano Nacional de Educação (PNE) 2014-2024 e dá outras providências. Diário Oficial da União. Brasília/DF, 26/06/2014. 2014. Disponível em:

http://www.planalto.gov.br/ccivil_03/_ato2011-2014/2014/lei/l13005.htm. Acesso em: 27/01/2018.

CERISARA, A. B. O Referencial Curricular Nacional para a Educação Infantil no cont exto das reformas. Educação \& Sociedade, v. 23, n. 80, p. 326-345, 2002.

\section{CONSELHO FEDERALDE PSICOLOGIA (CFP). Referências Técnicas para}

Atuação de Psicólogas (os) na Educação Básica. Brasília: CFP, 2013.

COSTA, A.S.; GUZZO, R. S. L. Psicólogo escolar e educação infantil:um estudo de caso. Escritos sobre Educação, v. 5, n. 1, p. 05-12, 2006.

FERREIRA, C. A. Investigando os sentidos da atuação profissional de Psicólogos na Educação Infantil. 2015. 152f. Dissertação (Mestrado em Psicologia) - Universidade Federal de Santa Catarina, Florianópolis, 2015.

KRAMER, S. As crianças de 0 a 6 anos nas políticas educacionais no Brasil: educação infantil e/é fundamental. Educação \& Sociedade, v. 27, n. 96, p. 797-818, 2006. 
MACARINI, S. M.; MARTINS, G. D. F.; VIEIRA, M. L. Promovendo saúde e desenvolvimento na Educação Infantil: uma atuação da Psicologia. Paideia, v. 19, n. 43, p. 231-237, 2009.

MARINHO-ARAÚJO, C. M.; ALMEIDA, S. F. C. Psicologia Escolar: construção e consolidação da identidade profissional. $2^{a}$ ed. Campinas: Editora Alínea, 2008.

MOREIRA, J. A.S.; LARA, A. M. B. Políticas públicas para a educação infantil no Brasil (1990-2001). Maringá: Eduem, 2012.

PATTO, M. H. S. Psicologia e Ideologia: uma introdução crítica à psicologia escolar. São Paulo: T. A. Queiroz, 1984.

PATTO, M. H. S. Introdução à Psicologia Escolar. 4a ed. São Paulo: Casa do Psicólogo, 2010.

ROCHA, R. M. G. Perspectivas e contradições da Educação Infantil hoje. In: HERMIDA, J. F. Educação Infantil: política e fundamentos $2^{a}$ ed. Joao Pessoa: Ed. Universitária da UFPB, 2009. p. 47-60.

SILVANA, F.S. S.; OLIVEIRA, G. F. Psicologia e Educação Infantil: desafios atuais. Id online, v. 10, n. 33, p. 282-293, 2017.

SOUZA, M. P. R. Psicologia Escolar e políticas públicas em Educação: desafios contemporâneos. Em Aberto, v. 23, n. 83, p. 129-149, 2010.

SOUZA, M. P. R.; RAMOS, C. J. M.; LIMA, C. P; BARBOSA, D. R.; CALADO, V. A.; Y AMAMOTO, K. A tuação do Psicólogo na Educação: Análise de publicações científicas brasileiras. Psicologia da Educação, s/v. n. 38, p. 123-138, 2014.

VIEIRA, V.; HANSEN, J.; VIEIRA, M. L. Psicologia Escolar na Educação Infantil: atuação e prevenção em saúde mental. Barbarói, v. 2, n. 31, p. 72-92, 2009.

VOKOY, T.; PEDROZA, R. L. S. Psicologia Escolar em Educação Infantil: reflexões de uma atuação. Psicologia Escolar e Educacional, v.9, n. 1, p. 95104, 2005.

ZENDRON, A. B. F.; KRA VCHYCHYN, H.; FORTKAMP, E. H. T.; VIEIRA, M. L. Psicologia e educação infantil: possibilidades de intervenção do psicólogo escolar. Barbarói, s/v, n. 39, 108-128, 2013.

Recebido em: 18 de maio de 2018. Aprovado em: 05 de abril de 2019. 